\title{
AVALIAÇÃO DA QUALIDADE MICROBIOLÓGICA DA CARNE DE FRANGO COMERCIALIZADA NO MUNICÍPIO DE PONTA GROSSA - PARANÁ
}

\section{EVALUATION OF MICROBIOLOGICAL QUALITY OF CHICKEN SOLD IN THE CITY OF PONTA GROSSA - PARANA}

\author{
Fernanda Rogenski Penteado ${ }^{1}$, Luís Antônio Esmerino² \\ 1 Aluna do Curso de Farmácia da Universidade Estadual de Ponta Grossa (UEPG). TCC \\ do Curso de Farmácia. \\ 2 Departamento de Análises Clínicas, Laboratório de Microbiologia Clínica, \\ Universidade Estadual de Ponta Grossa (UEPG), Avenida Carlos Cavalcanti, 4748, \\ Uvaranas, 84030-900, Ponta Grossa, PR, Brasil. E-mail: <esmerino@uepg.br> \\ Recebido para publicação em 20/11/2010 \\ Aceito para publicação em 06/03/2011
}

\section{RESUMO}

O objetivo do presente trabalho foi avaliar as condições higiênico-sanitárias de cortes de frangos resfriados, comercializados em cinco pontos de venda no município de Ponta Grossa - PR. Foram analisadas 50 amostras de 10 lotes no período de março a maio de 2008. As análises microbiológicas realizadas foram: determinação do NMP de coliformes totais, coliformes a $45^{\circ} \mathrm{C} / \mathrm{g}$, Escherichia coli e Enterococcus spp, contagem em placas de aeróbios mesófilos, Staphylococcus aureus e fungos; pesquisa de Salmonella spp e Pseudomonas spp. Nossos resultados mostraram contaminação de origem fecal máxima de $6,55 \times 10^{-2} \mathrm{NMP} / \mathrm{g}$ dentro, portanto, dos padrões estabelecidos pela legislação atual. A presença de Salmonella spp foi negativa em todas as amostras. No geral, nossos resultados mostraram contagens de microrganismos inferiores àquelas estabelecidas na legislação vigente, o que atesta uma boa qualidade higiênico-sanitária para a carne de frango comercializada na cidade.

Palavras-Chave: Carne de frango. Qualidade. Legislação.

\begin{abstract}
This study evaluated the sanitary conditions of refrigerated chicken cuts sold at five selling points in the city of Ponta Grossa-PR. Fifty samples from 10 lots were analyzed from March to May 2008. The following microbiological analyses were conducted: determination of the most probable number of total coliforms, coliforms at $45^{\circ} \mathrm{C} / \mathrm{g}$, Escherichia coli, and Enterococcus spp, plate counts of aerobic mesophiles, Staphylococcus aureus, and fungi; survey for Salmonella spp
\end{abstract}


and Pseudomonas spp. The results showed contamination of fecal origin ranging from 0.31 to $655 \mathrm{MPN} / \mathrm{g}$, therefore within the standards established by the current law. The presence of Salmonella spp was negative in all samples. In general, the results showed microorganism counts lower than those established by the current law, which attests to the good sanitary quality of chicken meat sold in the city.

Keywords: Chicken meat. Quality. Legislation.

\section{Introdução}

A carne de frango vem assumindo um papel importante na alimentação humana, principalmente por ser um produto saudável e de baixo custo. Dessa forma, sua qualidade microbiológica e o estudo da incidência de microrganismos potencialmente patogênicos têm importância para a saúde pública. A carne de frango deve apresentar uma carga bacteriana baixa e a pesquisa de bactérias e/ ou indicadores de condições higiênico-sanitárias auxilia na verificação da qualidade (SILVA et al., 2002).

A ave chega ao abatedouro com uma contaminação microbiana própria, que pode ser modificada ou aumentada durante as diferentes etapas do processamento e obtenção da carne. A biota contaminante se restringe principalmente à superfície e à pele, pois as mesmas são contaminadas pela água, pelo processamento e pelo manuseio das aves. Em geral, a biota reflete os microrganismos do abate e de etapas do processamento, com uma predominância de bactérias Gram-negativas (JAY, 2005).

$\mathrm{Na}$ carne de frango são frequentemente isoladas Salmonella spp, Staphylococcus aureus e Escherichia coli, possíveis causadores de danos à saúde e de toxinfecções alimentares, além de microrganismos associados à deterioração da carne, tais como Pseudomonas (SPOTO et al., 1999 ; MIYAGUSKU et al., 2003).
Salmonella spp representa o mais importante microrganismo envolvido em contaminações de alimentos à base de frango (RUCKERT et al., 2006). Estudos mostram que a ocorrência deste microrganismo em carcaças de frangos pode variar de $0,24 \%$ a $85 \%$ (KIMURA et al., 2004). Nogueira et al. (2005) consideram as salmoneloses como uma das principais doenças transmitidas por alimentos, devido ao seu caráter endêmico, alta morbidade e difícil controle. Além dos ovos e produtos processados com eles, perus e frangos são identificados como veículo de surtos (DICKEL et al., 2005).

A presença de bactérias do grupo coliformes fecais ou coliformes termotolerantes em alimentos é interpretada como indicador de contaminação fecal, ou seja, de condições higiênico-sanitárias insatisfatórias, indicando uma possível ocorrência de patógenos entéricos (DELÚ et al., 2006; CARDOSO et al., 2005). De acordo com a RDC ANVISA $n^{0}$ 12/2001 (BRASIL, 2001), para carnes resfriadas ou congeladas in natura de aves (carcaças inteiras, fracionadas ou cortes), deve-se pesquisar obrigatoriamente coliformes a $45^{\circ} \mathrm{C} / \mathrm{g}$ e a tolerância para amostra indicativa é de $10^{4}$ UFC/g (se obtido por contagem em placa) ou $10^{4}$ $\mathrm{NMP} / \mathrm{g}$ (se obtido por metodologia do número mais provável) (BRASIL, 2001).

A presença de coliformes totais em alimentos, embora menos significativa do que de coliformes termotolerantes, é considerada uma 
indicação útil de contaminação pós-sanitização ou pós-processo, evidenciando práticas de higiene e sanitização aquém dos padrões requeridos para o processamento de alimento (SILVA et al., 2007).

Bactérias aeróbias mesófilas são também usadas como indicadores de qualidade microbiológica e de acordo com Cardoso et al. (2005) sua presença em grande número indica matéria-prima excessivamente contaminada, limpeza e desinfecção das superfícies inadequadas, higiene insuficiente e condições inapropriadas de tempo e temperatura durante a produção e conservação dos alimentos.

Os enterococos são bactérias geralmente isoladas do intestino grosso do homem e dos animais e, portanto, são consideradas agentes comensais. A presença dessas bactérias no trato gastrointestinal da ave pode levar à contaminação da carne durante o abate. As espécies de Enterococcus faecalis e Enterococcus faecium geralmente são predominantes (FOULQUIÉ-MORENO et al., 2006). Outros microrganismos, como os fungos, podem ser encontrados juntamente com as leveduras do gênero Candida e Rhodoturola nas diferentes etapas do processamento (JAY, 2005).

Portanto, vários grupos ou espécies de microrganismos podem ser utilizados na avaliação da qualidade dos alimentos. Esses microrganismos, conhecidos como microrganismos indicadores, quando presentes, podem fornecer informações sobre a ocorrência de contaminação de origem fecal, presença de patógenos ou deterioração potencial do alimento, além de indicarem condições sanitárias inadequadas durante o processamento, produção ou armazenamento (FRANCO; LANDGRAF, 2003).

Sendo assim, o presente trabalho, teve como objetivo verificar a qualidade microbiológica da carne de frango comercializada no município de
Ponta Grossa, através da pesquisa de microrganismos indicadores.

\section{Material e Métodos}

As amostras de cortes comerciais de carcaças de frangos (coxa, sobrecoxa, frango a passarinho e asas) foram obtidas de cinco pontos de venda, localizados no município de Ponta Grossa, Paraná. Foram coletados cinco lotes de marcas diferentes e após cinco semanas as mesmas marcas foram novamente coletadas nos respectivos pontos. No total, 10 lotes foram analisados, sendo que cada lote deveria estar refrigerado e embalado em bandejas de isopor, com no mínimo cinco unidades do produto. As unidades foram analisadas individualmente e no total foram efetuadas 50 análises em duplicata. A coleta seguiu as orientações estabelecidas na Resolução RDC ANVISA n ${ }^{\circ} 12$, de 2 de janeiro de 2001 (BRASIL, 2001).

A técnica utilizada foi a da lavagem superficial com $300 \mathrm{~mL}$ de diluente (água peptonada tamponada estéril). O caldo de lavagem ou caldo de enxaguadura foi utilizado para as análises microbiológicas e foi considerado como sendo sem diluição $\left(10^{\circ}\right)$. Na sequência diluições decimais foram realizadas em água peptonada tamponada estéril até a diluição $10^{-5}$ e as análises microbiológicas foram realizadas segundo N. Silva et al. (2007).

A técnica de semeadura em profundidade foi utilizada para determinação de microrganismos aeróbios mesófilos, fungos e leveduras e Staphylococcus aureus (confirmados depois pela prova da coagulase). Os resultados foram expressos em Unidades Formadoras de Colônias por grama (UFC/g).

Para a determinação de coliformes totais, coliformes fecais ou termotolerantes $\left(45^{\circ} \mathrm{C}\right)$ e Enterococcus spp utilizou-se o método do Número 
Mais Provável (NMP). Para esses microrganismos foram realizados os testes presuntivo e confirmatório. Os resultados positivos geraram um código que foi consultado em uma tabela com limite de confiança de $95 \%$ para a enumeração do Número Mais Provável por grama da amostra $(\mathrm{NMP} / \mathrm{g})$.

$\mathrm{Na}$ contagem de Escherichia coli os caldos EC (incubados a $45^{\circ} \mathrm{C}$ ) positivos foram repicados em Agar Eosina Azul de Metileno (EMB) e a identificação foi realizada através de provas bioquímicas com a utilização do Manual de Identificação de Enterobactérias NEWPROV. Para identificação trabalhamos com uma probabilidade de $90 \%$.

Para a pesquisa de Salmonella spp o caldo de enxaguadura foi incubado em estufa a $35^{\circ} \mathrm{C}$ por 24 horas para o pré-enriquecimento (MACHADO et al., 1988). Após a incubação, alíquotas de 5,0 mL, em duplicata, foram transferidas para $45 \mathrm{~mL}$ de Caldo Tetrationato e as misturas obtidas foram incubadas a $35^{\circ} \mathrm{C}$ por 18-24 horas, para enriquecimento seletivo. Após incubação as culturas foram semeadas com alça, por esgotamento em duplicata, nos meios de Ágar Salmonella-Shigella (SS) e Ágar Xilose Lisina Desoxicolato (XLD). Colônias suspeitas foram inoculadas em uma série bioquímica para enterobactérias NEWPROV e no Ágar Tríplice Açúcar Ferro (TSI). Cepas com reações sugestivas foram submetidas à confirmação através de prova de soro-aglutinação com soro polivalente somático PROBAC (CARAMORI JÚNIOR et al., 2005). Como controle de qualidade utilizou-se uma cepa de referência: Salmonella typhimurium ATCC 14028.

Na pesquisa de Enterococcus spp seguiu-se o método dos tubos múltiplos ou NMP. Amostras positivas no teste presuntivo foram submetidas ao teste confirmatório. Assim, cada tubo positivo em Caldo Dextrose Azida foi semeado em placa contendo Ágar Bile Esculina e em caldo com 6,5\% de $\mathrm{NaCl}$. As placas e tubos foram incubados a $35^{\circ} \mathrm{C}$ durante 24 horas. Os enterococos são tolerantes ao sal e crescem no caldo com $6,5 \% \mathrm{NaCl}$. No Ágar Bile Esculina o crescimento dos enterococos indica resistência à bile e o escurecimento do meio indica hidrólise da esculina (SILVA, et al., 2007). Para identificação de Enterococcus faecalis foram realizadas provas bioquímicas específicas (OPLUSTIL et al., 2004).

Na pesquisa de Pseudomonas spp utilizou-se o Ágar Cetrimida. As colônias características de Pseudomonas aeruginosa (verde-azulada e fluorescente) e de Pseudomonas fluorescens (amarela, esverdeada, fluorescente) foram consideradas como prova positiva presuntiva da presença.

\section{Resultados e Discussão}

Inicialmente calculou-se o NMP ou UFC por mililitro de água de lavagem (enxaguadura), em função das diluições inoculadas. Considerou-se a água originária da lavagem, com a concentração inicial de microrganismos recolhida da amostra sem diluição $\left(10^{\circ}\right)$. Os resultados foram calculados e expressos em UFC/g, para contagens em placas e em $(\mathrm{NMP} / \mathrm{g})$ para a enumeração em tubos. A Tabela 1 mostra os resultados obtidos para os parâmetros microbiológicos e corresponde à média de cinco amostras em duplicata de cada lote.

Considerando a Resolução $n^{\circ} 12 / 2001$ da ANVISA, que exige a determinação de coliformes a $45^{\circ} \mathrm{C}$ (coliformes termotolerantes ou coliformes de origem fecal) em carnes resfriadas in natura de aves (carcaças inteiras, fracionadas ou cortes), os lotes apresentaram contaminação de origem fecal variando de 0,31 a $655 \mathrm{NMP} / \mathrm{g}$ e a legislação estabelece o máximo de $10^{4} \mathrm{NMP} / \mathrm{g}$. Assim, todos os lotes analisados foram considerados aceitáveis para o consumo (Tabela 1 ). 
Tabela 1 - Parâmetros microbiológicos para a média das amostras nos diferentes lotes analisados.

\section{Parâmetros microbiológicos}

000
0
0
0
0
0
0
0
0
0
0
0
0
0
0
0
0
0
0
0
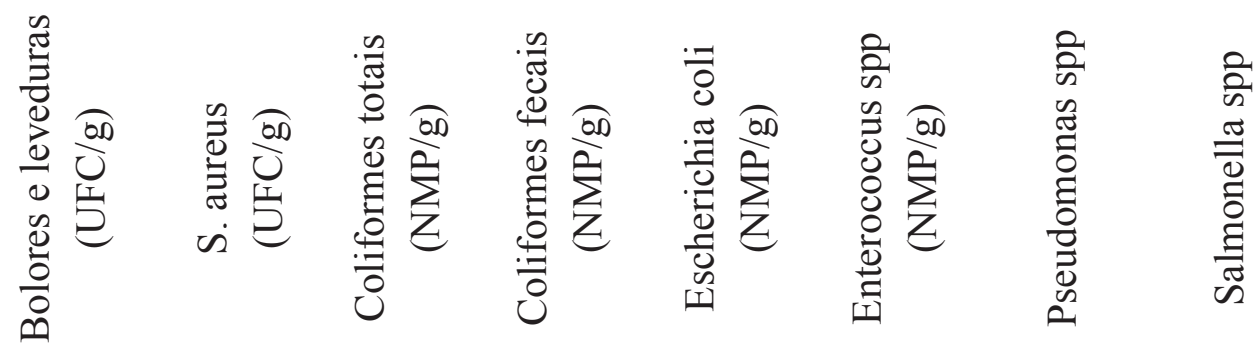

\begin{tabular}{cccccccccc}
\hline LA E1 & $6,0 \times 10^{4}$ & $<10$ & $<10$ & 33 & 655 & 6,7 & $<0,3$ & P $5 / 5$ & A $5 / 5$ \\
\hline LB E1 & $5,6 \times 10^{3}$ & $4,5 \times 10^{2}$ & $<10$ & 48 & 0,31 & $<0,3$ & 16,6 & P $4 / 5$ & A $5 / 5$ \\
\hline LC E2 & $5,3 \times 10^{2}$ & $2,9 \times 10^{3}$ & $<10$ & 14,9 & 2,4 & 2,2 & 1,4 & P 5/5 & A $5 / 5$ \\
\hline LDE2 & $2,3 \times 10^{3}$ & $2,3 \times 10^{2}$ & $<10$ & 8,7 & 1,0 & 1,0 & 1,9 & P $1 / 5$ & A 5/5 \\
\hline LE E3 & $3,4 \times 10^{3}$ & $3,3 \times 10^{2}$ & $<10$ & 157 & 179 & 143 & 13,5 & P 5/5 & A 5/5 \\
\hline LF E3 & $3,2 \times 10^{3}$ & $1,9 \times 10^{2}$ & 12 & 180 & 65 & 65 & 0,9 & P 5/5 & A 5/5 \\
\hline LG E4 & $4,2 \times 10^{3}$ & $4,7 \times 10^{2}$ & $<10$ & 410 & 331 & 245 & $<0,3$ & P 5/5 & A 5/5 \\
\hline LH E4 & $2,3 \times 10^{3}$ & $3,1 \times 10^{2}$ & 18 & 170 & 110 & 84 & $<0,3$ & P $1 / 5$ & A 5/5 \\
\hline LI E5 & $1,1 \times 10^{3}$ & $5,6 \times 10^{1}$ & 11 & 8 & 2,8 & 1,6 & 1,8 & P $1 / 5$ & A 5/5 \\
\hline LJ E5 & $6,7 \times 10^{3}$ & $4,4 \times 10^{2}$ & 47 & 58 & 3,2 & 3,0 & 2,6 & P 4/5 & A 5/5 \\
\hline
\end{tabular}

L - Lotes (A,B,C,D,E,F,G,H,I,J)

E - Estabelecimentos $(1,2,3,4,5)$

$\mathrm{P}$ - Presença (número de amostras positivas/número de amostras testadas).

A - Ausência (número de amostras negativas/número de amostras testadas).

$<10 \mathrm{UFC} / \mathrm{g}$ - Ausência de crescimento em todas as diluições inoculadas.

$<0,3 \mathrm{NMP} / \mathrm{g}-$ Tubos múltiplos negativos (0-0-0). 
Comparando nossos resultados com outros trabalhos observa-se que Delú et al. (2006) em suas análises de cortes de frango não encontraram amostras fora dos parâmetros legais. Cardoso (2005), entretanto, relatou que 20,7\% das amostras se apresentavam em condições insatisfatórias ou impróprias para o consumo.

A legislação em vigor não estabelece parâmetros microbiológicos para coliformes totais. Nossas amostras foram submetidas a esta análise para se conhecer a carga microbiana e assim avaliar as condições higiênico-sanitárias dos cortes de frango, uma vez que estes parâmetros refletem na qualidade da matéria-prima, na higiene do ambiente e no cuidado com que os manipuladores manuseiam os alimentos. Nossos resultados para coliformes totais variaram entre 8,0 e $4,1 \times 10^{2} \mathrm{NMP} / \mathrm{g}$ (Tabela 1). Esses resultados foram inferiores aos relatados por Cardoso et al. (2005) que observaram

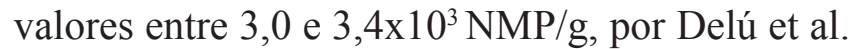
(2006) com valores de $3,0 \times 10^{1}$ e $2,6 \times 10^{3} \mathrm{NMP} / \mathrm{g}$ e por Silva et al. (2002) que relataram contagem de $4,33 \times 10^{2}$ e $2,4 \times 10^{4} \mathrm{NMP} / \mathrm{g}$.

Para bactérias aeróbias mesófilas a legislação atual (Resolução n $n^{0}$ 12/2001 da ANVISA) também não estabelece parâmetros, entretanto vários autores ainda citam os parâmetros da CNNPA (1978) e do Código Sanitário do Estado de São Paulo (1992). A contagem observada para aeróbios mesófilos variou entre $5,3 \times 10^{2}$ e $6,0 \times 10^{4}$ UFC/g, dentro dos parâmetros exigidos pela CNNPA (1978) e pelo Código Sanitário do Estado

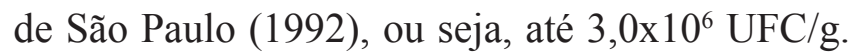
Cardoso et al. (2005) observaram contagens menores entre $3 \times 10^{2}$ e $7,4 \times 10^{3} \mathrm{UFC} / \mathrm{g}$. A contagem deste grupo tem sido usada como indicador de qualidade higiênica, indicando se a limpeza, a desinfecção e o controle da temperatura durante os processos de tratamento industrial, transporte e armazenamento foram realizados de forma adequada. Esse parâmetro permite ainda obter informação sobre a provável vida-útil do produto (CARDOSO et al., 2005; SILVA, et al., 2002).
A análise de bolores e leveduras apresentou contagens médias variando entre $10^{1}$ a $10^{3} \mathrm{UFC} / \mathrm{g}$. Hoffmann et al. (1997) relataram variações maio-

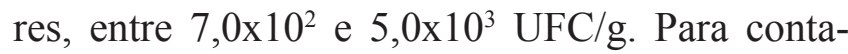
gens de bolores e leveduras em carne de frango os parâmetros microbiológicos não estão estabelecidos. A presença de fungos possui uma importância menor na deterioração de aves, exceto quando os antibióticos são utilizados para suprimir o crescimento bacteriano. Quando são usados, os bolores se tornam os principais agentes da deterioração.

Nossos resultados detectaram a presença de Staphylococcus aureus em 40\% das amostras analisadas, com contagens variando entre 11 e 47 UFC/g (Tabela 1). A CNNPA (1978) considera aceitável até $10^{3} \mathrm{UFC} / \mathrm{g}$ do alimento. Dessa forma todos os lotes analisados estavam adequados para o consumo. Freitas et al. (2001) encontraram também contagens baixas de $10^{1}$ a $10^{2} \mathrm{UFC} / \mathrm{g}$ em carcaças de frango resfriadas. Machado et al. (1988) relataram 40\% de amostras fora dos padrões estabelecidos pela CNNPA. SILVA et al. (2002) relataram resultados semelhantes aos nossos com $43 \%$ das amostras contaminadas. A contagem de Staphylococcus aureus em alimentos é interpretada como indicativo de contaminação a partir dos manipuladores, bem como da limpeza e sanitização inadequada dos materiais e equipamentos, refletindo condições higiênicosanitárias inadequadas (SIQUEIRA, 1995; FRANCO; LANDGRAF, 2003). Além disso, a presença de $S$. aureus é uma indicação de perigo potencial devido à enterotoxina estafilocócica, pois sendo termorresistente, não é destruída ou inativada durante o tratamento térmico (CARMO et al., 2002; FRANCO; LANDGRAF, 2003).

Para Pseudomonas spp nossos resultados mostraram a presença desse microrganismo em $70 \%$ das 50 amostras analisadas e em todos os lotes pelo menos uma das amostras estava contaminada (Tabela 1). O estabelecimento E3 apresentou a maior contaminação e o E5 a menor (Tabela 1). 
Pseudomonas spp estão entre as bactérias que geralmente causam a deterioração da carne de aves (MIYAGUSKU et al., 2003) e desta forma sua presença deve ser vista com atenção.

As contagens de Enterococcus spp variaram entre 0,3 a $16,6 \mathrm{NMP} / \mathrm{g}$ e foram detectadas em $60 \%$ dos lotes analisados (Tabela 1). Esses microrganismos foram pesquisados através da técnica do número mais provável, por tubos múltiplos, que detecta bactérias na ordem de 0,3 $\mathrm{NMP} / \mathrm{g}$. Dessa forma, nos $40 \%$ em que não foram detectados Enterococcus spp, a contagem foi de $<0,3 \mathrm{NMP} / \mathrm{g}$ o que equivale ao código $0-0-0$. A pesquisa de Enterococcus spp não é obrigatória segundo a legislação em vigor e poucos trabalhos pesquisaram esses microrganismos. Gomes (2007) relatou contagens de 3,8 UFC/g de Enterococcus spp em peitos de frango, resultado semelhante aos nossos.

O interesse no uso de Enterococcus spp como indicador de higiene e contaminação fecal pode ser justificado pelo fato de que esse gênero é geralmente mais tolerante à refrigeração quando comparado com Escherichia coli e outros coliformes e parece sobreviver por mais tempo durante a estocagem refrigerada de carcaças de carnes (INGHAM; SCHMIDT, 2000). Entretanto, ao contrário do grupo dos coliformes totais e fecais, não há um nível estabelecido para relacionar a presença de Enterococcus spp e a qualidade higiênica de um determinado produto (GOMES, 2007).

Nas análises não detectamos contaminação por Salmonella (Tabela 1). Nossos resultados foram semelhantes aos relatados por Cardoso et al. (2000) e Delú et al. (2006). Nogueira et al. (2005) encontraram $4,5 \%$ das carcaças resfriadas contaminadas por bactérias desse gênero. Carvalho et al. (2005) detectaram em 13,5\% e M. Silva et al. (2004) relataram contaminação em 43\% das carcaças analisadas. A Salmonella é uma bactéria que pode atingir o homem e os animais. Os alimentos são os principais veículos de transmissão, principalmente os de origem animal, como ovos, aves, carnes e produtos lácteos (SILVA et al., 2007).

\section{Conclusão}

Com base nos resultados obtidos e comparando-os com os parâmetros estabelecidos na Legislação Brasileira observamos que todas as amostras estavam em conformidade com a RDC ANVISA $12 / 2001$ para coliformes a $45^{\circ} \mathrm{C}$ (coliformes termotolerantes ou coliformes de origem fecal) e para Salmonella spp.

Nossos resultados mostraram contagens dos microrganismos indicadores da qualidade higiênico-sanitária inferiores àquelas estabelecidas na legislação atualmente em vigor o que atesta uma boa qualidade para a carne de frango comercializada na cidade de Ponta Grossa, Paraná.

\section{REFERÊNCIAS}

BRASIL. Agência Nacional de Vigilância Sanitária ANVISA. Resolução RDC n⿳ 12, de 2 de janeiro de 2001. Regulamento técnico sobre os padrões microbiológicos para alimentos. Disponível em: <http//www.anvisa.gov. br>. Acesso em: 04 fev. 2008.

CARAMORI JUNIOR, J. G.; ROÇA, R. O.; PINTO, J. P. A.N.; ANDREATTI FILHO, R. L.; MENDES, A. A.; PADOVANI, C. R.; MOSCARDI JR., E.; RAGHIANTI, F. Avaliação da presença de Salmonella spp em carcaças de frangos de corte, alimentados com rações com probióticos e prebióticos. Higiene Alimentar, v.19, n. 133, p. 72-78, 2005.

CARdoso, A. L. S. P.; TESSARI, E. N. C.; CASTRO, A. G. M.; KANASHIRO, A. M. I. Pesquisa de Salmonella spp coliformes totais, coliformes fecais, mesófilos, em carcaças e produtos derivados de frango. Arquivos do Instituto Biológico, Sao Paulo, v.67, n. 1, p. 25-30, 2000.

CARDOSO, A. L. S. P.; CASTRO, A. G. M.; TESSARI, E. N. C.; BALDASSI, L; PINEIRO, E. S. Pesquisa de Salmonella spp coliformes totais, coliformes fecais, mesófilos, em carcaças e cortes de frango. Higiene Alimentar, v.19, n.128, p. 144-150, 2005.

CARMO, L. S.; DIAS, R. S.; LINARDI, V. R. Food poisoning 
due to enterotoxigenic strains of Staphylococcus present in minas cheese and raw milk in Brazil. Food Microbiology, v. 14, p. 9-14, 2002.

CARVAlHO, A. C. F. B.; CORTEZ A. L. L. Salmonella spp. em carcaças, carne mecanicamente separada, lingüiças e cortes comerciais de frango. Ciência Rural, v.35, n.6, p.1465-1468, 2005.

CNNPA. Comissão Nacional de Normas e Padrões para Alimentos. Padrões Microbiológicos. Resol. n n 13/78. Ministério da Saúde. p. 269-73, 1978.

DELÚ, M. A. F.; SBAMPATO, C. G.; MENDONÇA, A. T.; ICCOLI, R. H; MAIA, S. C.Avaliação microbiológica de cortes de frango resfriado, comercializados no município de Lavras, MG. Higiene Alimentar, v. 20, n. 138, p.83-85, 2006.

DICKEL, E. L.; SANTOS, L. R.; RODRIGUES, L. B.; VALLE, S. F; CECATTI, D. Ocorrência de Salmonella em abatedouros de aves com tecnologia totalmente automatizada (grande porte), semi automatizada (médio porte) e semi automatizada (pequeno porte). Higiene Alimentar, v.19, n.131, p. 62-67, 2005.

FRANCO, B. D. G; LANDGRAF, M. Microbiologia dos alimentos. $2^{\mathrm{a}}$. edição. São Paulo: Livraria Atheneu, 2003.

FREITAS, M. F. L.; MOTA, R. A.; VILELA, S. M. O.; SENA, M. J. BEZERRA, R. Cepas de Staphylococcus spp. isoladas de carcaças de frango comercializadas na cidade do Recife - PE, Brasil. Ciência Animal Brasileira, v. 2, n. 2, p.139-145, 2001.

FOULQUIÉ MORENO, M. R.; SARANTINOPOULOS, P.; TSAKALIDOU, E.; DE VUYST, L. The role and application or enterococci in food and health. International Journal of Food Microbiology, v. 106, p. 1- 24, 2006.

GOMES, B. C. Enterococos em amostra de alimentos e água: avaliação da virulência e do desempenho como indicadores de higiene. Paulo, 2007, 151p. Dissertação (Doutorado em Ciências Farmacêuticas) - Universidade de São Paulo (USP).

HOFFMANN, F. L; PAGNOCCA, F. C; FAZIO, M. L. S; VINTURIN, T. M. Estudo higiênico sanitário de diferentes tipos de iogurte. Boletim do Centro de Pesquisa e Processamento de alimentos, v.15, n.2, p.187-196,1997.

INGHAM, S. C; SCHMIDT, D. Alternative Indicator bacteria analyses for evaluating the sanitary condition of beef carcasses. Journal of Food Protection, v.63, p.51-55, 2000 .

JAY, J. M. Microbiologia de alimentos. 6. ed. Porto Alegre: Artmed, 2005

KIMURA, A. C.; REDDY, V.; MARCUS, R.; CIESLAK, P. R.; MOHLE-BOETANI, J. C.; KASSENBORG, H. D.; SEGLER, S. D.; HARDNETT, F. P.; BARRETT, T.;
SWERDLOW, D. L. Emerging Infections Program FoodNet Working Group. Chicken consumption is a newly identified risk factor for sporadic Salmonella enterica serotype enteriditis infections in the United States: a case-control study in FoodNet sites. Clinical Infectious Diseases, v. 38, suppl 3, p. 244-252, 2004

MACHADO, N. A. N.; ZAPATA, J. F. F.; VASCONCELOS, M. E. L.; BARROSO, M. A. T. Qualidade microbiológica do frango abatido em estabelecimentos de diferentes portes. Revista Ciência Agronômica, v.19, n.1, p.13-18, 1988

MIYAGUSKU, L.; CHEN, F.; LEITÃO M. F. F.; BAFFA, O. Avaliação microbiológica e sensorial da vida-útil de cortes de peito de frango irradiados. Ciência e Tecnologia de Alimentos. v. 23, suppl., pp. 7-16, 2003.

NOGUEIRA, N. A. P.; VERDE, J. C. L.; BASTOS, G. M; BRITO, E. C. O.; OLIVEIRA, M. T.; SOARES, M. I. M.; AGUIAR, A. C. L. Bactérias do gênero Salmonella em carcaças de frangos comercializadas em Fortaleza, CE. Higiene Alimentar, v.19, n.137, p.87-89, 2005.

OPLUSTIL, C. A.; ZOCCOLI, C. M.; TOBOUTI, N. R. SINTO, N. R. Procedimentos básicos em microbiologia clínica. 2. ed. São Paulo: Sarvier, 2004.

RÜCKERT , D. A. S.; PINTO, P. S. A.; RODRIGUES, A. C. A.; BEVILACQUA, P. D.; PINTO, M. S. Métodos de pesquisa de Salmonella $s p$ durante o abate de frangos. Higiene Alimentar, v.20, n.146, p. 49-54, 2006.

SÃO PAULO (Estado). Código sanitário: Decreto n ${ }^{\circ} 12.342$ de 27 de setembro de 1978: regulamento da promoção e recuperação da saúde no campo da competência da Secretária de estado da saúde (revisto e atualizado até dezembro de 1990). 5. ed. São Paulo: IMESP, 1992.

SENA, M. J. Perfil epidemiológico, resistência a antibióticos e aos conservantes nisina e sistema lactoperoxidase de Staphylococcus sp. Isolados de queijo coalho comercializados em Recife-PE. Belo Horizonte. 2000, 75p. Dissertação (Doutorado). Escola Veterinária. Universidade Federal de Minas Gerais (UFMG).

SILVA, J. A. Microrganismos patogênicos em carne de frango. Higiene Alimentar, v.12, n.58, p. 9-14, 1998.

SILVA, J. A; AZERÊDO, G. A.; BARROS, C. M. R.; COSTA, E. L.; FALCÃO, M. M. S. Incidência de bactérias patogênicas em carne de frango refrigerada. Higiene Alimentar, v.16, n.100, p. 97-101, 2002.

SILVA, M. C. D.; RAMALHO L. S. FIGUEIREDO, E. T. Salmonella sp em ovos e carcaças de frango in natura comercializadas em Maceió, AL. Higiene Alimentar, v. 18, n.121, p.80-84, 2004.

SILVA, N.; JUNQUEIRA, V. C. A; SILVEIRA, N. F. A. TANIWAKI, M. H.; SANTOS, R. F. S.; GOMES, R. A. $\mathrm{R}$. Manual de métodos de análise microbiológica de 
alimentos. 3. ed. São Paulo: Varela, 2007.

SIQUEIRA, R. S. Manual de microbiologia de alimentos. Centro de pesquisas de Tecnologia Agroindustrial de Alimentos - CTAA. Brasília: EMBRAPA - SPI, 1995.

SPOTO, M. H. F.; GALLO, C. R.; DOMARCO, C. R.; ALCARDE, A. R.; WALDER, J. M. M.; BLUMER, J. Radiação gama na redução da carga microbiana de filés de frango. Ciência e Tecnologia de Alimentos, v.19, n.3, p.397-400, 1999. 